\begin{tabular}{c} 
JOURNAL OF APPLIED SMART ELECTRICAL \\
NETWORK AND SYSTEMS (JASENS) \\
\hline ISAS
\end{tabular}

\title{
VERTICAL TAKE OFF LANDING (VTOL) UNTUK DROP KITS PADA QUADCOPTER
}

\author{
Mochammad Junus ${ }^{1}$, Junaedi Adi Prasetyo ${ }^{2}$, Ridho Hendra Yoga Perdana ${ }^{3}$ \\ Jurusan Teknik Elektro, Politeknik Negeri Malang \\ Jurusan Teknik Informatika, Politeknik Negeri Banyuwangi \\ Jurusan Teknik Elektro, Politeknik Negeri Malang \\ ${ }^{1}$ moch.junus@polinema.ac.id, ${ }^{2}$ junaedi.prasetyo@poliwangi.ac.id, ${ }^{3}$ ridho.hendra@polinema.ac.id
}

\begin{abstract}
A structure due to natural disasters often occurs in Indonesia, and this is caused by the location of Indonesia in the path of earthquakes and volcanoes. Logistics delivery in the form of medicines and food has been hampered, and this is acknowledged by the Indonesian government, which experienced many obstacles when it had to reach an isolated location due to land transportation lines being cut off. So it was designed an Unmanned Aerial Vehicle (UAV) or drone that can deliver survival kits to some places that are isolated due to natural disasters autonomously. Flight orders will be made through the Mission Planner software, which is then sent to the drone using $433 \mathrm{MHz}$ telemetries. Survival kits carried by drones will be dropped using a servo to a predetermined location. The work of Vertical Take-Off Landing (VTOL) for Drop Kits has successfully carried out a mission to deliver survival kits to 4 different locations in one flight. By using the $433 \mathrm{MHz}$ Telemetry, the drone can travel a maximum distance of 120 meters in 5 minutes 10 seconds with a 9 Ah battery capacity.
\end{abstract}

Keywords: Drones, Telemetry 433 MHz, Kits, Vertical Take Off, Quadcopter

\begin{abstract}
Abstrak
Rusaknya insfratruktur jalan akibat bencana alam sering terjadi di Indonesia, hal ini disebabkan oleh letak Indonesia pada jalur gempa bumi dan gunung berapi. Pengiriman logistik berupa obat-obatan dan makanan menjadi terhambat, hal ini diakui oleh pemerintah Indonesia yang mengalami banyak kendala ketika harus mencapai lokasi yang terisolir karena putusnya jalur transportasi darat. Sehingga dirancanglah sebuah Unmanned Aerial Vehicle (UAV) atau drone yang dapat mengantarkan survival kits ke beberapa tempat yang terisolir karena bencana alam secara autonomous. Perintah terbang akan dibuat melalui software Mission Planner yang kemudian dikirimkan pada drone menggunakan telemetry $433 \mathrm{MHz}$. Survival kits yang dibawa terbang drone akan dijatuhkan menggunakan servo menuju lokasi yang sudah ditentukan sebelumnya. Hasil kerja Rancang Bangun Vertical Take Off Landing (VTOL) untuk Drop Kits telah berhasil melakukan misi mengantarkan survival kits ke 4 lokasi yang berbeda dalam sekali terbang. Dengan menggunakan Telemetry $433 \mathrm{MHz}$ drone tersebut dapat menempuh jarak maksimal 120 meter dalam waktu 5 menit 10 detik dengan kapasitas baterai 9 Ah.
\end{abstract}

Kata kunci: Drones, Telemetry 433 MHz, Kits, Vertical Take Off, Quadcopter

Diterima Redaksi : 02-06-2020 | Selesai Revisi : 12-06-2020 | Diterbitkan Online : 30-06-2020

\section{Pendahuluan}

Wilayah Indonesia berada pada jalur gunung berapi dan gempa bumi hal ini mengakibatkan seringnya terjadi bencana alam [1]. Pengelolaan sistem bantuan logistik termasuk hal yang tak kalah penting pada penanganan bencana alam, membutuhkan koordinasi yang baik, kecepatan dan mutu pelayanan yang optimal pengembangan sistem surveillance pasca bencana [2].

Menurut Mario Arturo Ruiz Estrada dalam papernya, setiap bencana alam selalu ada kemungkinan besar kerusakan infrastruktur, sistem transportasi, akses sistem telekomunikasi, dan layanan dasar [3]. Dalam pendistribusian logistik kemanusiaan bencana biasanya menghadapi kendala yaitu kondisi badan jalan dan jembatan yang terputus akibat longsor [4]. Dikutip Tempo.Co disebutkan bahwa pemerintah masih mengalami sejumlah kendala mendistribusikan bantuan karena sulitnya mencapai lokasi yang terisolasi. Oleh sebab itu, diperlukan solusi untuk pengiriman bantuan logistik terutama berupa obat-obatan ke posko-posko secara tepat yaitu dengan cara memanfaatkan teknologi yang ada.

Pemanfatan UAV atau drone sebagai pengirim logistik gerak cepat menjadi salah satu alternatife yang dapat digunakan[5-7], akan tetapi tidak dapat menemukan rute 
paling efektif untuk tujuan lebih dari 1. Penggunaan 5 drone juga dilakukan pada bidang yang lain yaitu untuk pemantauan ekologi dan insulator keramik[8,9]. Selain itu untuk mengendalikan drone diperlukan suatu system kontrol yang baik[10], tetapi kontrol tersebut masih menggunakan PID system. Penggunaan drone untuk pengiriman logistic sudah banyak digunakan seperti membawa obat-obatan. UAV yang dapat didesain 6 . kompak dan cukup ringan dapat menggantikan tugas manusia dalam pengiriman cepat tanpa harus mendarat, tapi cukup terbang rendah mendekat ke lokasi korban dan menjatuhkan survival kits atau bahan-bahan logistik.

Untuk itu, dilakukan penelitian mengenai Rancang Bangun Vertical Take Off Landing (VTOL) untuk Drop Kits dengan memanfaatkan VTOL berjenis hexacopter dilengkapi dengan Global Positioning System (GPS) dan radio telemetry $433 \mathrm{MHz}$ sebagai pemantauan dengan pencarian rute efektif lebih dari 1 lokasi dropship sehingga memecahkan permasalahan pengiriman logistik berupa obat-obatan dengan cepat ke wilayah -wilayah yang terisolir karena tidak dapat dijangkau dengan transportasi darat

\section{Metode Penelitian}

Tahapan perencanaan pembuatan alat terdiri dari pembuatan perancangan sistem pada VTOL dan sistem drop kits, perencanaan penentuan lokasi untuk drop kits, perencanaan rancangan mekanis drop kits, dan perencanaan elektrik VTOL dan drop kits

Blok diagram sistem VTOL dan drop kits dapat dilihat pada Gambar 1. berikut

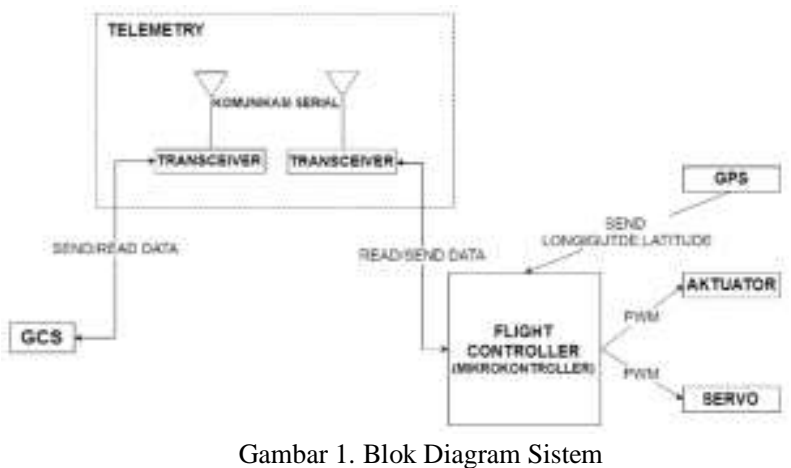

Berikut ini adalah fungsi dari masing-masing blok diagram sistem :

1. Ground Control Station (GCS) merupakan pemberi perintah droping kits

2. Tranceiver merupakan perangkat telemetry yang digunakan untuk mengirim dan menerima data GCS dan flight controller dengan komunikasi serial yang menggunakan media radio frekuensi. berfungsi sebagai kontroller utama untuk Bila pulsa lebih pendek dari $1500 \mathrm{~ms}$ maka akan memproses data dari GCS. (longitude, latitude) posisi tempat penjatuhan drop diberikan lebih lama dari $2000 \mathrm{~ms}$ maka poros motor kits.

Journal of Applied Smart Electrical Network and Systems (JASENS)
Current (BLDC) yaitu komponen yang mengubah energi menjadi gerak mekanis untuk menggerakkan atau mengendalikan suatu mekanisme atau sistem dan ESC yang memiliki peran untuk mengatur putaran pada motor sesuai arus yang di butuhkan oleh motor. mekanisme drop kits

Perencanaan lokasi drop kits terdapat 5 titik yang ditentukan terlebih dahulu pada Mission Planner.

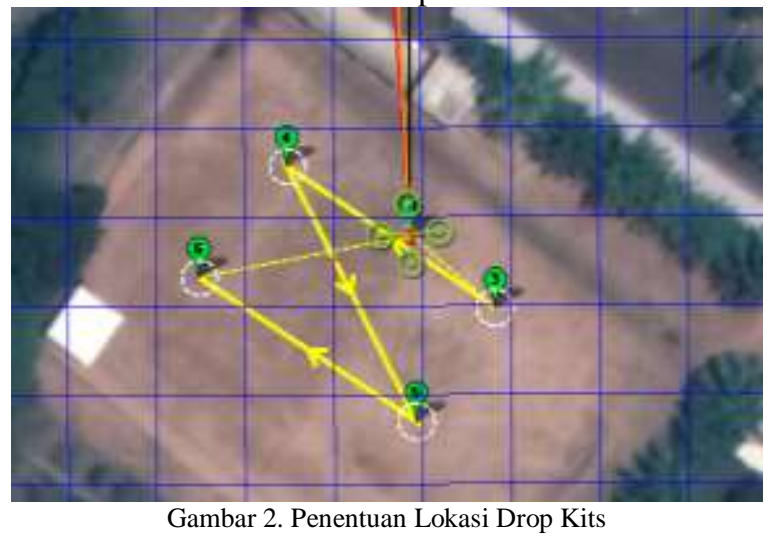

Perancangan sistem drop kits dibuat untuk mempermudah dalam realisasi alat yang akan dibuat. diagram alir sistem drop kits sebagai berikut :

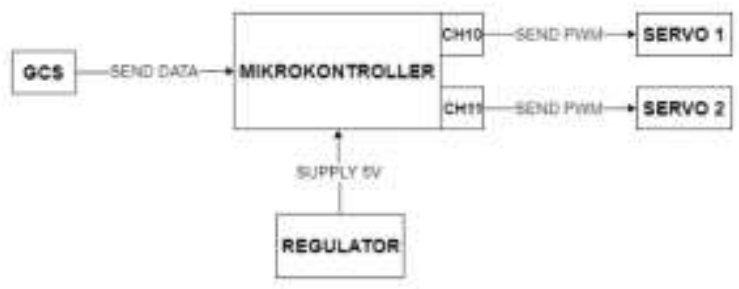

Gambar 3. Blok Diagram Sistem Drop Kits

Pada bagian masukan berupa data program yang dikirim dari GCS. Pada bagian keluaran berupa 2 servo yang digunakan sebagai penggerak mekanisme drop kits. Mekanisme drop kits dengan motor servo pada dasarnya memanfaatkan gaya gerak setengah lingkaran putaran atau 0 derajat sampai 180 derajat. Motor servo dikendalikan dengan memberikan sinyal modulasi lebar pulsa melalui pin $\mathrm{CH} 10$ dan $\mathrm{CH} 11$. Sinyal PWM sepenuhnya diatur oleh bagian pengendali yaitu mikrokontroller yang menerima input dari GCS. Sebagai berputar ke arah posisi 0 derajat atau ke kiri (berlawanan

\subsection{Perancangan Sistem Drop Kits}


servo akan berputar ke arah posisi 180 derajat atau ke yaitu command list waypoint secara bertahap hingga kanan (searah jarum jam). Dengan tambahan lengan selesai.

servo yang didesain seperti gambar 4 dan torsi servo yang besar, bisa mendorong logistik ke titik penjatuhan 2.4. Flight Time Position Hold

dan mengembalikan posisi lengan servo. Proses ini Flowchart untuk flight time position hold yang dilakukan secara berulang ulang sesuai dengan logistik digunakan untuk mempertahankan posisi dalam waktu yang dibawa.

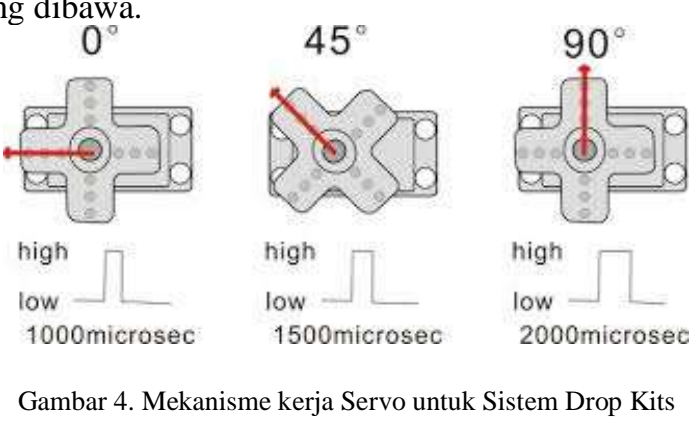

\subsection{Sistem Autonomous Mission}

Flowchart desain autonomous mission pada drone diperlihatkan pada gambar 5 .

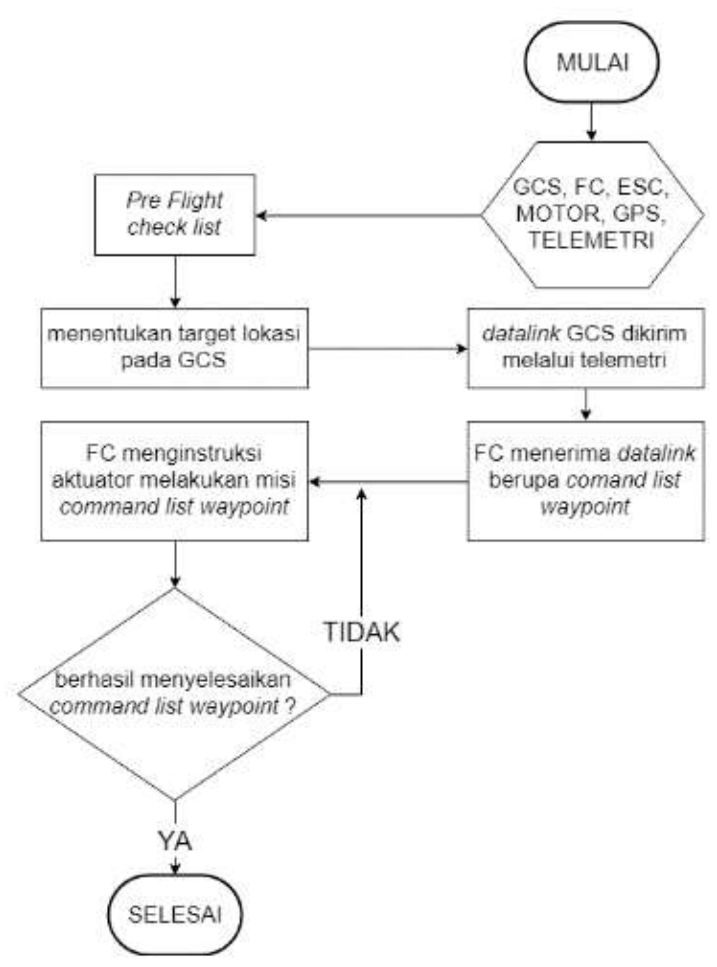

Gambar 5. Diagram Alir Sistem Autonomous Mission

Gambar 5 menjelaskan diagram alir dari sistem autonomous mission yang digunakan. Setelah inisialisasi GCS, ESC, motor, GPS, telemetri, dan pre flight check list telah terpenuhi sebelum proses terbang dilakukan, perlu dilakukan penentuan target lokasi yang akan dituju oleh drone dengan cara membuat flight plan melalui GCS. Datalink yang dihasilkan Mission Planner akan dikirim atau di upload via telemetri menuju Flight Controller (FC) pixhawk. FC pixhawk akan menginstruksikan aktuator untuk melakukan perintah tertentu diperlihatkan pada gambar 6

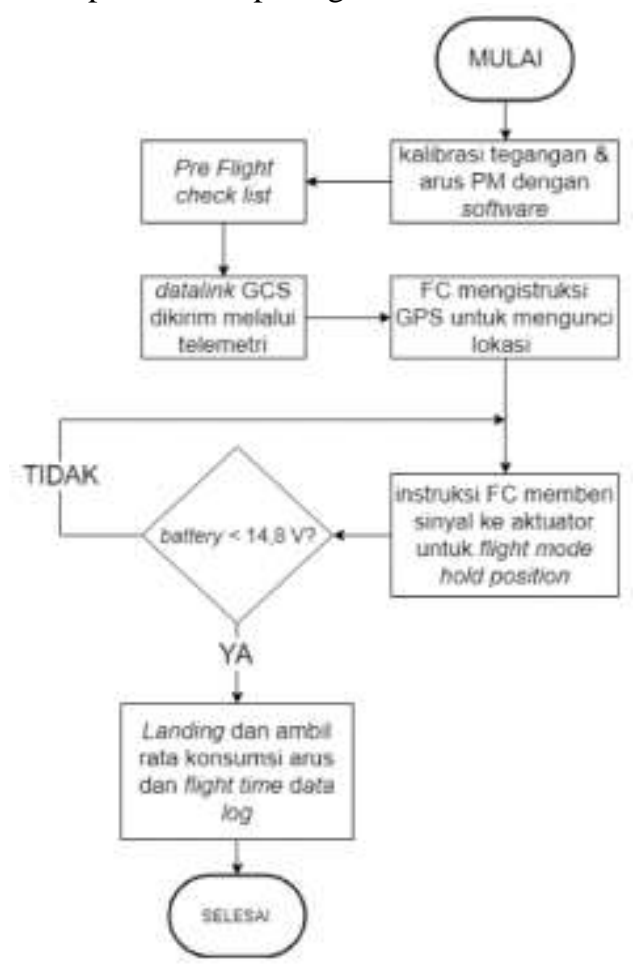

Gambar 6. Diagram alir Flight Time Position Hold

Flight time hold position merupakan upaya drone untuk mempertahankan posisi dalam waktu tertentu. Flight time position hold mengacu pada modul GPS dan sensor arus pada Power Module. Modul GPS akan mengunci lokasi drone dan sebisa mungkin untuk mempertahankan posisi drone di lokasi tersebut. Sensor arus power module akan mencatat perolehan konsumsi arus pada drone dalam setiap detik sehingga data dapat diolah untuk memperoleh rata - rata konsumsi arus dan memperoleh total waktu terbang atau flight time.

\section{Hasil dan Pembahasan}

\subsection{Pengujian Misi Menjatuhkan Drop Kits}

Pada pengujian ini bertujuan untuk mengetahui kesesuaian yang dihasilkan dari proses menjatuhkan drop kits secara acak. Hasil pengujian ditunjukkan pada tabel 1.

Tabel 1

Pengujian Misi Menjatuhkan Drop Kits 


\begin{tabular}{ccccc|cccc|cccc}
\hline No & $\begin{array}{c}\text { Urutan titik } \\
\text { drop hits }\end{array}$ & \multicolumn{3}{c|}{$\begin{array}{c}\text { Delay (detik) per titik } \\
\text { drop lits }\end{array}$} & \multicolumn{3}{|c|}{$\begin{array}{c}\text { Deviasi logistik dari } \\
\text { titik drop kits (meter) }\end{array}$} \\
\hline 1. & 1 & 2 & 3 & 4 & 5 & 7 & 4 & 10 & 1,0 & 2,0 & 1,5 & 1,0 \\
2. & 2 & 1 & 4 & 3 & 8 & 11 & 8 & 4 & 0,9 & 0,6 & 0,5 & 1,3 \\
3. & 3 & 4 & 1 & 2 & 5 & 5 & 4 & 13 & 0,5 & 3,0 & 2,5 & 2,7 \\
4. & 4 & 3 & 2 & 1 & 5 & 6 & 9 & 13 & 0,7 & 1,1 & 1,3 & 0,8 \\
\hline
\end{tabular}

Hasil yang diperlihatkan pada tabel 1, diperoleh pada pengujian menjatuhkan drop kits yang dapat dideskripsikan bahwa terdapat 3 informasi yaitu :

- Urutan titik drop kits, informasi ini dimaksudkan untuk mendefinsikan titik yang harus dituju terlebih dahulu oleh drone ketika melakukan misi menjatuhkan drop kits.

- delay (detik) per titik drop kits, informasi ini memuat perolehan waktu riil penjatuhan drop kits yang dihitung setelah drone telah mencapai berhenti ke titik yang ditentukan.

- deviasi logistik dari titik drop kits (meter), informasi ini menjelaskan penyimpangan titik jatuh logistik dari titik drop kits yang telah ditentukan.

\subsection{Pengujian Pembacaan Nilai Sensor Arus Power Module}

Pada pengujian ini bertujuan utuk mengetahui luaran yang dihasilkan dari pembacaan nilai sensor arus power module dengan perhitungan secara teori.

Tabel 2. Pengujian Sensor Arus Power Module

\begin{tabular}{|c|c|c|}
\hline $\begin{array}{c}A U W(A l l U p \\
\text { Weight) } \mathrm{Kg}\end{array}$ & DURASI & ARUS \\
\hline \multirow{13}{*}{$\begin{array}{c}\text { 4,2 (dengan } \\
\text { Beban) }\end{array}$} & 10:02:12.1 & 0.30804 \\
\hline & $10: 02: 32.5$ & 61.17453 \\
\hline & 10:02:53.1 & 61.94672 \\
\hline & 10:03:13.8 & 61.21039 \\
\hline & $10: 03: 34.5$ & 59.0264 \\
\hline & 10:03:55.1 & 63.56225 \\
\hline & $10: 04: 36.5$ & 59.9402 \\
\hline & 10:04:57.1 & 63.83915 \\
\hline & $10: 05: 38.5$ & 62.511 \\
\hline & 10:05:59.1 & 65.86685 \\
\hline & 10:06:19.8 & 62.18015 \\
\hline & 10:06:40.5 & 62.87029 \\
\hline & 10:07:22.1 & 66.22234 \\
\hline \multirow{12}{*}{$\begin{array}{c}3.75 \text { (Tanpa } \\
\text { Beban) }\end{array}$} & $15: 59: 53.2$ & 0.284506 \\
\hline & 16:00:33.6 & 33.7493 \\
\hline & 16:01:14.1 & 35.97316 \\
\hline & 16:01:54.6 & 35.97132 \\
\hline & $16: 02: 35.1$ & 34.87354 \\
\hline & $16: 03: 15.7$ & 35.86104 \\
\hline & $16: 03: 56.2$ & 36.41186 \\
\hline & $16: 05: 17.3$ & 37.55375 \\
\hline & $16: 05: 57.8$ & 36.03932 \\
\hline & $16: 06: 38.3$ & 37.78146 \\
\hline & $16: 07: 18.9$ & 38.27604 \\
\hline & 16:07:59.4 & 37.69159 \\
\hline
\end{tabular}

\begin{tabular}{cccc}
\hline \multicolumn{3}{c}{$16: 08: 39.9$} & 36.79469 \\
$16: 09: 20.4$ & 35.98234 \\
\hline & Tabel 3. Perbedaan Kapasitas Baterai \\
\hline AUW kg & set flight time & $\begin{array}{c}\text { battery } \\
\text { capacity }\end{array}$ & $\begin{array}{c}\text { battery } \\
\text { remaining }\end{array}$ \\
\hline 3.75 & 10 minutes & $9000 \mathrm{mAh}$ & $4121 \mathrm{mAh}$ \\
$3,75+100$ & 10 minutes & $9000 \mathrm{mAh}$ & $4052 \mathrm{mAh}$ \\
$3,75+200$ & 10 minutes & $9000 \mathrm{mAh}$ & $3872 \mathrm{mAh}$ \\
$3,75+300$ & 10 minutes & $9000 \mathrm{mAh}$ & $3777 \mathrm{mAh}$ \\
$3,75+400$ & 10 minutes & $9000 \mathrm{mAh}$ & $3678 \mathrm{mAh}$ \\
\hline
\end{tabular}

Menghitung arus dan lama waktu terbang drone dengan membawa beban

Berat total drone $=4,2 \mathrm{Kg}$

Thrust tiap motor $=4,2 / 6=0,7 \mathrm{Kg}$

Karena thrust tiap motor $0,7 \mathrm{Kg}$ maka kita menggunakan Arus dengan thrust diatas nilai $0,7 \mathrm{Kg}$ dapat dilihat pada data sheet.

$$
\begin{aligned}
\text { I tot } & =\mathrm{I} \text { (setiap motor) } \times 6 \\
& =10,8 \times 6 \\
& =64,8 \text { Ampere } \\
\text { Time } & =\text { capacity } x \text { discharge } / \mathrm{I} \\
& =9 \text { Ah } \times 80 \% / 64,8 \\
& =0,111 \mathrm{jam} \\
& =6,6 \text { menit }
\end{aligned}
$$

- Menghitung arus dan lama waktu terbang drone tanpa membawa beban

Berat drone $=3,8 \mathrm{Kg}$

Thrust tiap motor $=3,8 / 6=0,63 \mathrm{Kg}$

Karena thrust tiap motor $0,63 \mathrm{Kg}$ maka kita menggunakan arus dengan thrust diatas nilai 0,63 $\mathrm{Kg}$ dapat dilihat pada data sheet.

$$
\begin{aligned}
\text { I tot } & =\mathrm{I} \text { (setiap motor) } \times 6 \\
& =7,4 \times 6 \\
& =44,4 \text { Ampere } \\
\text { Time } & =\text { capacity } x \text { discharge } / \mathrm{I} \\
& =9 \text { Ah } \times 80 \% / 44,4 \\
& =0,162 \mathrm{jam} \\
& =9,7 \text { menit }
\end{aligned}
$$

Dari hasil pengujian terdapat perbedaan nilai arus pada saat drone terbang dengan membawa beban dan tanpa membawa beban. Ketika membawa beban konsumsi arus lebih besar yaitu 61,84 A dibandingkan dengan tanpa membawa beban yang konsumsi arusnya lebih kecil yaitu 36,32 A. Beban yang dibawa drone juga mempengaruhi lama waktu terbang drone. Hasil yang diperoleh lama waktu terbang ketika membawa beban yaitu 5 menit 10 detik. Untuk lama waktu terbang ketika tanpa membawa beban yaitu 9 menit 27 detik. 
Pada hasil perhitungan secara teori diperoleh nilai konsumsi arus sebesar 64,8 A untuk terbang dengan beban dan 44,4 A untuk terbang tanpa membawa beban. Dari perbedaan arus ini juga mempengaruhi lama waktu terbang drone. Seperti pada tabel 2 dari hasil uji lapangan diperoleh lama waktu terbang ketika membawa beban yaitu 5 menit 10 detik, sedangkan dari hasil perhitungan teori diperoleh nilai 6,6 menit atau 6 menit 36 detik. Lama waktu terbang ketika tanpa membawa beban berdasarkan uji lapangan yaitu selama 9 menit 27 detik sedangkan, dari hasil perhitungan teori diperoleh hasil lama waktu terbang drone yaitu 9,7 menit atau 9 menit 42 detik.

Terdapat berbedaan capacity battery dari 5 percobaan pada Tabel 3. Semua percobaan di atur dengan waktu sebesar 10 menit untuk uji flight time dan battery capacity sebesar $9000 \mathrm{mAh} 9000 \mathrm{mAh}$ merupakan kondisi battery terisi penuh. dari hasil pengujian, didapat battery remaining yang bervariasi. untuk AUW $3,75 \mathrm{~kg}$ didapat $4121 \mathrm{mAh}$, AUW 3,85kg didapat $4052 \mathrm{mAh}$, AUW 3,95kg didapat $3872 \mathrm{mAh}$, AUW 4,05kg didapat $3777 \mathrm{mAh}$, AUW 4,15kg didapat $3678 \mathrm{mAh}$.

\subsection{Pengujian Jarak Jangkau Telemetri $433 \mathrm{MHz}$}

Pada sub-bab ini dijelaskan tentang pengujian jarak jangkau telemetry $433 \mathrm{MHz}$ untuk mengetahui jarak jangkau telemetri yang dilihat dari kualitas penerimaan sinyal.

Tabel 4 Penerimaan Sinsyal Telemetri 433 Mhz

\begin{tabular}{|c|c|c|c|}
\hline \multirow{2}{*}{ No } & \multirow{2}{*}{$\begin{array}{c}\text { Jarak } \\
(\mathrm{m})\end{array}$} & \multicolumn{2}{|c|}{ Penerimaan Signal } \\
\hline & & RSSI & $\mathrm{dBm}$ \\
\hline \multirow{2}{*}{1} & \multirow{2}{*}{0} & 186 & -24 \\
\hline & & 186 & -24 \\
\hline \multirow{2}{*}{2} & \multirow{2}{*}{10} & 121 & $-56,5$ \\
\hline & & 121 & $-56,5$ \\
\hline \multirow{2}{*}{3} & \multirow{2}{*}{20} & 91 & $-71,5$ \\
\hline & & 91 & $-71,5$ \\
\hline \multirow{2}{*}{4} & \multirow{2}{*}{30} & 87 & $-73,5$ \\
\hline & & 87 & $-73,5$ \\
\hline \multirow{2}{*}{5} & \multirow{2}{*}{40} & 75 & $-79,5$ \\
\hline & & 78 & -78 \\
\hline \multirow{2}{*}{6} & \multirow{2}{*}{90} & 65 & $-84,5$ \\
\hline & & 65 & $-84,5$ \\
\hline \multirow{2}{*}{7} & \multirow{2}{*}{100} & 55 & $-89,5$ \\
\hline & & 56 & -89 \\
\hline \multirow{2}{*}{8} & \multirow{2}{*}{110} & 53 & $-90,5$ \\
\hline & & 53 & $-90,5$ \\
\hline \multirow{2}{*}{9} & \multirow{2}{*}{120} & 57 & $-88,5$ \\
\hline & & 57 & $-88,5$ \\
\hline 10 & 130 & - & - \\
\hline
\end{tabular}

Berdasarkan Tabel 4 Peneriman Sinyal Telemetry $433 \mathrm{MHz}$ diperoleh jarak maksimal penerimaan yaitu 120 meter karena pada jarak 130 meter sudah tidak dapat menerima sinyal dan koneksinya sangat lama. Penerimaan sinyal maksimum dari radio Telemetry 433 $\mathrm{MHz}$ diperoleh pada jarak 0 meter dengan nilai RSSI sebesar 186 dan -24 dBm sedangkan, penerimaan sinyal minimum diperoleh pada jarak 120 meter dengan nilai RSSI sebesar 57 dan -88,5 dBm. Dari nilai RSSI tersebut dikonversi dalam satuan $\mathrm{dBm}$.
Pengujian penentuan rute efektif

Pada pengujian pencarian rute diperlihatkan pada tabel 5 .

\begin{tabular}{cc}
\multicolumn{2}{c}{ Tabel 5. Pengujian Ruter Efektif } \\
\hline Target & Hasil \\
\hline H-1-2-3-4-5-6-H & H-1-2-3-4-5-6-H \\
H-2-4-6-1-3-5-H & H-2-4-6-1-3-5-H \\
H-3-4-5-6-1-2-H & H-3-4-5-6-1-2-H \\
H-5-6-4-3-2-1-H & H-5-6-4-3-2-1-H \\
H-5-4-3-1-2-6-H & H-5-4-3-1-2-6-H \\
\hline
\end{tabular}

Pada tabel 5 diperlihatkan target rute dan hasil yang didapatkan dalam percobaan. Didapatkan data percobaan yang sesuai dengan target yang diharapkan, dengan drone berawal dari home $(\mathrm{H})$ dan memutari titik yang sudah di tetapkan kemudian kembali ke home.

\section{Kesimpulan}

Berdasarkan penelitian yang dilakukan dapat disimpulkan :

1. Dengan menggunakan Mission Planner dapat dilakukan kalibrasi drone yang dapat menyeimbangkan gerak drone pada saat terbang dan juga dapat membuat perintah VTOL untuk Drop Kits pada 4 titik berbeda

2. Lama waktu terbang drone ketika membawa beban sebesar 1,8 Kg ialah 5 menit 10 detik dengan ratarata arus 61,84 Ampere. Sedangkan, lama waktu terbang drone ketika tanpa membawa beban ialah 9 menit 20 detik dengan rata-rata arus 36, 32 Ampere.

3. Capasity battery remaining didapat hasil yang bervariasi. Untuk AUW 3,75kg didapat $4121 \mathrm{mAh}$, AUW 3,85kg didapat $4052 \mathrm{mAh}$, AUW 3,95kg didapat $3872 \mathrm{mAh}$, AUW 4,05kg didapat 3777 $\mathrm{mAh}, \mathrm{AUW} 4,15 \mathrm{~kg}$ didapat $3678 \mathrm{mAh}$

4. Peneriman Sinyal Telemetry $433 \mathrm{MHz}$ diperoleh jarak maksimal penerimaan yaitu 120 meter dengan nilai RSSI sebesar 186 dan -24 dBm karena pada jarak 130 meter sudah tidak dapat menerima sinyal dan koneksinya sangan lama

5. Proses pencarian rute efektif didapatkan hasil yang sesuai dengan target yaitu sebesar $100 \%$.

\section{Daftar Rujukan}

[1] C. Rusmiyati, "Penanganan Dampak Sosial Psikologis Korban Bencana Merapi," Informasi, vol. 17, 2012.

[2] L. Trisnantoro, "Mengelola Bencana di Sektor Kesehatan: Membutuhkan Pendekatan Ilmiah," Jurnal Manajemen Pelayanan Kesehatan, vol. 9, 2006.

[3] M. A. R. ESTRADA, "How Unmanned Aerial Vehicles-UAV's (or Drones) Can Help in Case of Natural Disasters Response and Humanitarian Relief Aid?," researchgate.net, 2017.

[4] M. D. E. F. Nancy L. Damanik, "MODEL Distribusi Bantuan Logistik Kemanusiaan Pada Saat Bencana Banjir Dengan Memperhitungkan Data Iklim," Jurnal Ilmu Kebencanaan (JIKA) Pascasarjana Universitas Syiah Kuala, vol. 2, 2015.

[5] E. De Reyes and J. Macneill, "Can cargo drones solve air freight's logjams? A drone startup says its big vertical-takeoff flier would be quick to land, load, and take off again," in IEEE Spectrum, vol. 
57, no. 6, pp. 30-35, June 2020, doi: 10.1109/MSPEC.2020.9099930.

[6] B. Kvæstad, Autonomous Drone with Object Pickup Capabilities, Norwegian, 2016

[7] S. R. S. M. K. M. Yusuf Tamtomi1, "Rancang Bangun Wahana Udara Tanpa Awak VTOL-UAV Sebagai Wahana Identifikasi Dini Kondisi Udara Berbasis Video Sender," Jurnal Rekayasa dan Teknologi Elektro, vol. 10, p. 194, 2016

[8] M. Sokač, P. Đurasek, I. Bačić and S. Puškarić, "UAV application in ecology: Data collecting with quad-copter equipped with Arduino based measurement platform," 2016 International Symposium ELMAR, Zadar, 2016, pp. 233-236, doi: 10.1109/ELMAR.2016.7731794.

[9] B. Ali, A. A. Khan, H. Nasir and H. Mannan, "Real Time Health Monitoring of Ceramic Insulators Using Quad-Copter," 2019 4th International Conference on Emerging Trends in Engineering, Sciences and Technology (ICEEST), Karachi, Pakistan, 2019, pp. 1-5, doi: 10.1109/ICEEST48626.2019.8981700.

[10]M. Qasim, E. Susanto and A. S. Wibowo, "PID control for attitude stabilization of an unmanned aerial vehicle quad-copter," 20175 th International Conference on Instrumentation, Control, and Automation (ICA), Yogyakarta, 2017, pp. 109-114, doi: 10.1109/ICA.2017.8068423. 